\title{
DEPURAÇÃO DOS SENTIDOS E ASCESE NO LIVRO VI DO Dí́lOGo SOBRE a MÚSICA DE SANTO AGOSTINHO
}

\author{
CLEARANCE OF THE SENSES AND ASCESIS IN BOOK VI OF THE \\ Dialogue ON THE MUSIC OF SAINT AUGUSTINE
}

\author{
NiLO CÉSAR BATISTA DA SILVA ${ }^{1}$ \\ Universidade Federal do Cariri (UFCA) - Brasil \\ nilobsilva@gmail.com
}

\begin{abstract}
RESUMO: o artigo visa propor uma reflexão sobre a doutrina do sensível, obtendo como ponto de partida o Livro Sexto do Diálogo sobre a música de Santo Agostinho (387-391). O objetivo é identificar elementos para uma 'estética' agostiniana, com base neoplatónica, cujo enfoque maior se dá na interiorização da alma. As nossas análises centralizam-se apenas no livro sexto, visando percorrer o itinerário da alma a Deus, por meio de uma gradual ascensão que segue desde a educação dos sentidos, a audição, a visão, perpassa a conversão do olhar até alcançar a transcendentalização perceptiva e sensorial, demonstrando em tais circunstâncias, que os movimentos da alma estão em analogia às harmonias e ritmos da música. De acordo com Agostinho, os ritmos da alma são realizados pela memória, porque mesmo no silêncio e até no sonho recordamos as paixões da alma no corpo como se a alma estivesse em plena atividade resistindo ou consentindo as paixões do corpo.
\end{abstract}

PALAVRAS-CHAVE: Agostinho. Sensações. Neoplatonismo. Música. Deus.

ABSTRACT: The article aims to propose a reflection on the doctrine of the sensible, taking as its starting point the Sixth Book of Dialogue on the Music of St. Augustine (387-391). The goal is to identify elements for an Augustinian 'aesthetic', with neoplatonic bases, whose main focus is on the interiorization of the soul. Our analyzes focus only on the sixth book, aiming at the soul's journey to God, through a gradual ascension that goes from the education of the senses, the hearing, the vision, goes through the conversion of the gaze until reaching the perceptual and sensorial transcendentalization, demonstrating in such circumstances that the movements of the soul are in analogy to the harmonies and rhythms of music. According to Augustine, the rhythms of the soul are realized by memory, because even in silence and even in the dream we recall the passions of the soul in the body as if the soul were in full activity resisting or allowing the passions of the body.

KEYWORDS: Augustine. Sensations. Neoplatonism. Music. God.

\section{INTRODUÇÃO}

O nosso estudo resulta de uma breve leitura do Sexto livro do Diálogo sobre a música, que foi escrito por Santo Agostinho entre os anos 387-391, durante a sua estadia como professor da disciplina de retórica em Milão. A obra também foi

\footnotetext{
${ }^{1}$ Professor de Filosofia Medieval na Universidade Federal do Cariri (UFCA) e membro do Programa de Pós-graduação em Filosofia da Universidade Federal de Sergipe (UFS).
} 
considerada uma referência do gênio agostiniano no campo da estética medieval, com o intuito pedagógico não apenas de preservar a herança clássica da ciência da música, mas, sobremaneira, conduzir o leitor a adentrar na incomensurável grandeza da espiritualidade da alma e nela descobrir o que há de mais belo, o espaço propício para a ascensão a Deus.

Antes, devemos dizer que seria de alguma forma despropositada de nossa parte, qualquer pretensão em atribuir, já na antiguidade tardia, por meio do pensamento agostiniano, uma teoria de estética medieval, mesmo sabendo que a invenção do termo "aisthesis" de toda maneira o antecede. A verdade é que, uma teoria sistemática de estética só aparece posteriormente no século XVIII, momento em que são publicados os estudos do filósofo alemão, Alexandre Gottlieb Baumgarten (1714-1762), com o objetivo de oferecer uma doutrina estética capaz de aliar sensação, isto é, o sentimento à racionalidade, no sentido de atribuir a faculdade do conhecer a legitimidade da capacidade de sentir. A teoria estética, mesmo sendo criação da Filosofia na modernidade, isso não significa dizer que os autores medievais ignorassem qualquer reflexão filosófica-teológica sobre a beleza, à exemplo temos Santo Agostinho, que em pleno século IV escrevendo um tratado sobre a música. O filósofo de Hipona era amante das artes liberais, lecionava essa disciplina ofertada no quadrivium que designava o conjunto das três artes do movimento: a palavra, o canto e a dança. A verdade é que, a inclinação pela reflexão filosófica sobre a natureza do belo, aguçou a intuição de muitos filósofos desde o princípio da História da Filosofia.

É surpreendente perceber que o De musica, apesar de sua importância no conjunto dos diálogos filosóficos de Agostinho, parece ser o menos examinado no vasto campo de estudos agostinianos recentes. Agostinho, em breve nota de suas Retratações, situa a relevância desta obra na formulação da visio Dei e, conforme suas notas, o conteúdo geral do livro baseia-se no princípio fundamental da filosofia pitagórica, o número como essência de todas as coisas e que, por meio do exercício dialético, a alma humana gradualmente poderia contemplar a essência divina.

\section{O LUGAR do DE MUSICA NA DIÁlETICA AGOSTINIANA}

O Diálogo sobre a música está inserido entre a primeira série dos escritos filosóficos de Agostinho, os quais reverberam, de alguma maneira, a dialética neoplatónica. Ao examiná-los brevemente percebemos que os temas dos diálogos são diversificados, bem como as abordagens e objetivos, alguns apresentam características apologéticas, outros de natureza mais complexa que incluem confrontos doutrinais, preocupações pedagógicas e convicções filosóficas. No conjunto dos Diálogos filosóficos o destaque se dá na forma como foi pensada a composição do De musica, primeiro por se distanciar dos exemplos de apologética, depois por recuar ao confronto doutrinal com os maniqueus que está presente em quase todos os escritos agostinianos.

Conforme escreve Mammì (1994), "a escrita do De música, apesar de acentuar o interesse em salvar a estrutura quantitativa da métrica antiga, acrescenta 
alguns elementos específicos, no campo da psicologia e da epistemologia agostiniana". Mas, para melhor situar a escrita do De musica, temos algumas ponderações a serem feitas; uma questão a se considerar é que na época de Agostinho continuavam em plena vigência à interpretação comum de dois aspectos essenciais da antiga ciência da música, uma vertente ética ou psicológica, e outra a vertente cósmica ou metafísica, que, por sua vez, confluíam na compreensão da natureza numérica do universo (cf. FAGUNDES, 2014, p. 34). Outro ponto relevante é que na mundividência romana era comum adotar as linhas gerais da filosofia esboçadas por Pitágoras e Platão, no intuito de decifrar a influência das matemáticas na cosmologia humana.

Neste marco referencial, ainda há de se considerar que os diálogos filosóficos escritos em Cassicíaco assimilam a influência do círculo intelectual de Milão, pois naquele momento, o neoplatonismo e o cristianismo estavam intimamente vinculados no âmbito das discussões filosóficas-teológicas lideradas por duas figuras importantes, a saber, Ambrósio, Bispo de Milão e o Sacerdote Simpliciano. Conforme mostram os estudos recentes, Agostinho toma conhecimento das obras de Plotino, por meio da tradução latina do africano, Mario Vitorino (300-363) ${ }^{2}$. Ao que se percebe, o neoplatonismo forneceu elementos suficientes para Agostinho realizar uma singular aventura intelectual, na qual transitaria do materialismo maniqueísta às certezas metafísicas, em busca da compreensão da noção de Deus, da espiritualidade da alma e sua ligação com o divino. ${ }^{3}$

Contudo, parece excessivamente reducionista, se não de todo errôneo, apesar de identificarmos acentuada influência neoplatónica nos escritos de Agostinho, pretender confinar o augustinismo no neoplatonismo, antes há de se distinguir as bases conceituais de ambos, em primeiro lugar, deve-se levar em conta a tese da metafísica da criação, postulada pelos autores cristãos no enfrentamento ao emanatismo gnósticos de raiz neoplatónica, além disso, talvez seja necessário frisar que o criacionismo, considerado uma patente da filosofia cristã, se deixe apontar contornos da teoria da participação platónica. Mas, identificamos um ponto no qual convergem as doutrinas, a neoplatónica e a Agostiniana, todavia observado por alguns estudos recentes, a saber, a ideia de que o trajeto da subida da alma em ascensão ao divino não é conduzido

\footnotetext{
${ }^{2}$ Há, portanto, um vasto consenso de que Agostinho tenha acessado escritos da estética plotinianos, "Sobre o Belo" (Eneadas I.6), ou por exemplo, o tratado, De regressu animae, que fora extraviado ao longo das traduções.

${ }^{3}$ É algo despropositado se pensar uma fusão analógica entre o Uno de Plotino e o Deus de Agostinho. Não será Plotino o autor de uma metafísica irracionalista na história da filosofia ocidental ao pretender afirmar que a inteligência não é o princípio último e que na raiz dos seres lhe escapa a toda determinação intelectual? "Plotino poderia considerar insolúvel o problema da construção racional e da realidade ao conceber o princípio radical como objeto de uma experiência sui generis, uma espécie de contato imediato e ininteligível muito distinto do conhecimento intelectual? Na verdade, admitir uma experiência com o absoluto que por sua natureza não é susceptível de nenhuma análise é admitir um dado opaco da inteligência". (Cf. BREHIER, 1953, p. 170). "A natureza do Uno é geradora de todas as coisas, razão porque não é nenhuma delas" (Cf. Enéadas, V, 1, 9, 3). Sendo o Uno nenhuma das coisas, ele é transcendente a toda determinação e sem essência. Isso quer dizer que não se assemelha a nenhuma essência dos entes; ele é a essência par excellence. O Uno é a Potência de todas as coisas, se ele não existisse, não existiria tampouco as coisas, nem sequer a inteligência, que é vida primeira e plena.
} 
diretamente, partindo dos objetos exteriores ao divino, mas se realiza, primeiramente, por meio de uma conversão no interior do espírito" (BRACHTENDORF, 2008, p. 136). Diga-se de passagem, que a noção de queda da alma através de sua orientação para as realidades sensíveis, causando o afastamento do ser absoluto, apresentem características quase consensuais entre ambos. Além disto, para Agostinho, assim como para Plotino, o itinerário da alma no seu retorno ao divino se dá no redescobrir-se dela mesma como dimensão espiritual.

Não há dúvida que a especulação agostiniana sobre a visio Dei, deve ser tributária da reflexão plotiniana sobre o uno, principalmente no momento em que Agostinho estava no cômpito de duas fortes correntes doutrinais e, consideravelmente convicentes ao jovem filósofo, a saber, o ceticismo romano ${ }^{4} \mathrm{e}$ o maniqueísmo; Em ambos, as análises conceituais de verdade e bondade que, em todo caso, deveria se distinguir do plano moral ou instrumental, precisamente por sua universalidade, estariam postas em crise. Do neoplatonismo Agostinho herda a principal noção para sua filosofia, "tudo o que é pode, na medida em que é, isto é, ser chamado bom”. Tudo o que é, enquanto é, logo, aspira a preservar a unidade, causa de sua existência. Num parágrafo conclusivo do De Musica, o hiponense escreve:

\begin{abstract}
Agora, bem, a harmonia começa pela unidade e é bela, graças à igualdade e à simetria, e se une pela ordem. Por essa razão, todo aquele que afirma que não existe natureza alguma que, para ser o que é, não deseje a unidade e se esforce por ser igual a si mesma, na medida de sua possibilidade, e que guarde sua própria ordem, seja em lugares ou tempos, ou mantenha sua própria conservação num corpo que sirva de equilíbrio; deve afirmar que tudo o que existe, e na medida em que existe, foi feito e fundado por um Princípio Único, por intermédio da beleza, que é igual e semelhante às riquezas de sua bondade pelo qual o Uno e o (outro) Uno que procede do Uno estão unidos por uma, por assim dizer, mui cara caridade (mus., VI, 16).
\end{abstract}

Agostinho assimilou do neoplatonismo a espiritualização da alma como atividade essencial da vida do homem. Traz como herança da especulação plotiniana a concepção de unidade, de certa forma, a noção de Deus como inefável. A unidade é para Plotino expressão da perfeição, o fundamento último do ser, o que constitui sua realidade verdadeira, superior a toda determinação e a toda forma, por isso, Plotino não identifica a unidade com o ser. Mas é a unidade que permite ao real ser, e ser pensado (Cf. Enéadas VI 6, 13, 1-16; VI 9, 2, 8-20).

\footnotetext{
${ }^{4}$ Refiro-me aos argumentos dos diálogos de Santo Agostinho, o Contra Acadêmico e o De beata Vida. O primeiro recebe grande influência das obras de Cícero, um breve momento em que Agostinho estava interessado no ceticismo, tais leituras resultaram na produção de Contra os Acadêmicos, integralmente dedicada aos argumentos do ceticismo dos acadêmicos da Nova Academia. Para os céticos, a felicidade será alcançada mediante a busca constante e diligente da verdade. Para Agostinho, isso não faz o menor sentido, uma vez que o homem somente pode ser feliz quando de posse da verdade. A contemplação da verdade é, para Santo Agostinho, a condição sine qua non da beatitude" (Cf. GILSON, 2006, p. 25).
} 


\section{ASCESE E DEPURAÇÃo doS SENTIDOS NO LiVRO SEXTO do DE MUSICA}

Agostinho é o amante da beleza, e quem ama a beleza, também ama a luz e a verdade. De todas as obras em que havia pensado acerca das artes liberais, levou a termo o Diálogo sobre a música (387-391), cuja composição pertence à primeira série de escritos produzidos em Cassicíaco, marcada pela forte influência da dialética neoplatónica. Com efeito, os diálogos filosóficos de Agostinho convergem para edificação de um ponto culminante de sua doutrina, a saber, a noção de interioridade da alma, onde habita a beleza e a verdade.

Através de uma breve leitura dos primeiros cinco livros do Diálogo sobre a música, logo percebemos que a preocupação geral do autor centraliza-se mais nas questões métricas em detrimento das definições musicais e funções que a música pode ou não exercer na educação dos sentidos. Não obstante, nos chama a atenção o conteúdo do livro sexto, pela imensa diferença que, de maneira geral, causa estranhamento na integração com o conjunto da obra. No esquema pedagógico da composição do livro sexto, a métrica deixa de ser a preocupação fundamental do autor para dar lugar à ampla investigação sobre a natureza da sensação e da beleza sensível em analogia com a beleza inteligível. Por sua vez, Agostinho avança gradualmente no campo da metafísica, sempre no esforço em provocar o leitor a aguçar o espírito por meio da experiência musical, para se obter uma verdadeira ascese.

Nos escritos de maturidade, o De trinitate, também identificamos o discurso agostiniano para justificar a depuração dos sentidos em busca da ascese, o argumento segue na tentativa em demonstrar a existência de um ideal inteligível, segundo o qual julgamos as coisas sensíveis, e por seu modo, fixamos as condições principais da beleza e da existência, o número, a unidade, a igualdade, a harmonia e a ordem. Conforme escreve Agostinho, as razões inteligíveis e incorpóreas com as quais julgamos as realidades sensíveis subsistem independentes do decurso do tempo, alcançá-las com a visão da mente é privilégio de poucos, e quando, na medida do possível, se alcançam, aquele que as alcançou não se fixa nelas, mas é repelido como o revérbero do olhar que é refletido, e constrói sobre uma realidade não transitória um pensamento transitório (De trin., XII,14. 23). De fato, se a melodia de um belo som musical que se desenvolve por um lapso de tempo for apreendida sem tempo, em silêncio interior e profundo, pode ser pensada durante tanto tempo quanto o tempo em que esse canto se pode ouvir; como quer que seja, aquilo que a visão do espírito daí colher, mesmo de passagem, e, como que deglutindo-o, depositar na memória, ao recordá-lo poderá de algum modo ruminálo e transpor para os seus conhecimentos o que assim tiver aprendido. Se for destruído por um esquecimento total, aquilo que de todo se tinha perdido há-de voltar, trazido pelo ensino, e será encontrado tal como era (ibdem).

Evidentemente que a música exerce uma importância singular no pensar agostiniano, contudo, o interesse pelos ritmos, o número, a modulação e, em geral, o seu apreço pela especulação musical, se justifica, em grande medida, pela influência que essa arte exerce enquanto instrumento de ascese espiritual. Diga-se de passagem, que o fundo de referência desse apreço pela beleza musical se 
encontra no particular interesse em examinar a capacidade de conhecimento da alma na sua relação com o corpo, a partir da eventualidade das sensações. A propósito, a especulação musical, enquanto teoria estética, constitui-se para o filósofo de Hipona, o ponto de partida para ampliar a sua compreensão de vários problemas filosóficos herdados da tradição filosófica, a começar pela relação entre uno e o múltiplo, o problema da natureza da alma e a relação com o seu corpo, isto é, problematizando o nível de influência corporal sobre a alma, desembocando, assim, numa possível teoria da sensação para o medievo.

Ao examinar a impressão dos ritmos musicais na alma humana, Agostinho tende a considerar como pressuposto inicial, dois elementos importantes para a apreensão dos movimentos da alma, a saber, a sensação e os sentidos; evidentemente que a sensação pertence à alma e os sentidos ao corpo. A sensação é a estrutura fundamental para a formação do conhecimento sensível; os sentidos do corpo são instrumentos de que a sensação serve para conhecer as realidades corpóreas, logo, percebemos que os sentidos do corpo participam da sensação e da estrutura da alma, mas, o corpo com os seus sentidos não formam, em hipótese alguma, o conhecimento, porém, apenas captam os dados sensíveis para que a alma, como sede da sensação, formule o conhecimento: "[...] por isso que sentir não é próprio do corpo, embora se disserte com agudez que os sentidos do corpo estão distribuídos de acordo com a diversidade de elementos corpóreos, a alma, à qual é inerente a potência do sentir por um corpo mais sutil" (De Genesi ad lit., III, 5, 7).

A sensação é uma experiência no corpo percebida em si mesmo pela alma. De fato, para Agostinho, a sensação jamais deve ser uma produção do corpo desvinculado da alma, pois sempre ocorre na alma por meio do corpo. Sendo pertença da alma, a sensação não é, porém, uma afecção da alma, porque, nesse caso, a sensação seria o efeito de uma ação do corpo sobre a alma, por causa de um princípio geral da filosofia agostiniana, herdeira do neoplatonismo, segundo o qual, aquilo que é inferior por natureza não pode agir sobre o que é superior. Esse princípio, como causa natural, proporcionou a Agostinho a necessidade de se estabelecer uma espécie de hierarquia ontológica, onde demonstre a ordem da relação existente entre os ritmos do corpo e os ritmos da alma - ou ritmos da razão.

De todo modo, a sensação é apresentada por Agostinho como forma da vida do espírito, efeito de uma atividade da alma sobre si mesma, originada da sua atenção para as realidades corpóreas que ela anima, e não de uma ação exercida pela matéria sobre uma alma passiva (FAGUNDES, 2014, p. 66). A sensação é uma ação primordial da alma, e não do corpo. Essa concepção, de imediato, subtrai o problema da ação do corpo sobre a alma, assim como se estabelecia na doutrina dos maniqueus. A convicção de que a sensação é uma atividade propriamente da alma, permitiu ao filósofo de Hipona lançar-se na procura do conhecimento de Deus, também circunscrito nas impressões sensíveis, ou seja, no sentido interior, no ritmo da memória, no horizonte onde reverbera o absoluto, habitável em cada alma humana. E, se a sensação é obra da alma que sente e pode ser alterada de acordo com a vontade, é válido afirmar que a alma só consegue seu equilíbrio, 
isto é, o "pondus meum" quando se volta do corpo, que lhe é sempre inferior, para o que lhe é sempre superior, a saber, Deus.

Através das sensações o nosso corpo sofre uma alteração por parte de outro corpo, por sua vez, nossa alma entra em ação, não só no sentido de que a alteração corpórea não lhe escapa, mas também no sentido de que ela "julga" as alterações. De toda maneira é relevante notar que, na concepção neoplatónica assumida por Santo Agostinho, através da impressão sensorial produzida nos órgãos corpóreos a alma vê o rastro das formas inteligíveis. Frisamos que, para Agostinho, isso nos conduz para a contemplação do inteligível, e assim, ao modo como a sensação se produz na alma. Plotino também interpreta como atividade da alma, a memória, os sentimentos, as paixões, as volições, e tudo que a ele se liga.

Como foi dito algumas vezes, a sensação deve ser considerada na sua dupla relação alma/corpo, privilegiando a sua origem na alma, pois a sensação é uma função da alma. ${ }^{5}$ Mas, sendo uma atividade da alma em seu movimento próprio, ela necessita do corpo para sentir, entretanto, não há como dissociá-la da relação alma/corpo, mesmo como tal, tendo sua origem na alma. Todavia, é a alma que sente, tem a visão da beleza, contempla a harmonia, percebe o sabor, cheira, deleita-se, o corpo reage como o outro da alma, isto é, não passa em sua funcionalidade de mera extensão sensível da alma. Acrescenta Agostinho, tantas vezes o corpo sofre os golpes das paixões da alma sem a menor capacidade de agir sobre ela.

A sensação é toda paixão sofrida no corpo, ou seja, constitui um duplo movimento composto de afecção do corpo e de ação da alma, afecção do corpo pela realidade exterior e ação da alma em resposta à afecção do corpo, as quais são sentidas no corpo pela alma. O próprio sentir é mover o corpo em resposta ao movimento que nele foi produzido (mus.,VI, 5,15). Há, portanto, dois princípios ativos nesse movimento da sensação, o corpo exterior e a alma, mas o corpo estabelece relação com a alma, o que supõe afirmar que só haveria sensação numa ação exercida de fora por um objeto sobre um órgão sensível. Existe algo de belo na experiência do sentir que o corpo reproduz (De ordine, II, 11,33).

Pensando desta forma, a sensação pode ser distinguida dos sensíveis. De fato, uma coisa é o sentido, outra, aquilo que passa pelo sentido. Como escreve Agostinho, o movimento belo afaga o sentido, posto que a significação bela do movimento afaga só o espírito (De ordine II, 11, 34 p.203). Isto quer dizer que o movimento dos corpos sensíveis torna-se prazeroso para os sentidos, mas a significação ou consentimento que podemos obter de um movimento sensível é uma atividade própria do espírito, haja vista que essa significação é dada pela cognição e alterada pelo crivo da vontade.

\footnotetext{
${ }^{5}$ A sensação tem relação com o conhecimento e com o espírito, enquanto os sensíveis, ao contrário, encontram-se inteiramente relacionados ao corpo. De acordo com Étienne Gilson, este é o ponto fundamental, a partir do qual as consequências se desenvolvem numa dupla direção. Os sensíveis contém em si a causa da sensação, mas não a sentem em nenhum grau. A doutrina agostiniana da sensação é uma reinterpretação do pensamento de Plotino, para quem a alma imprime em si as imagens dos objetos sensíveis percebidos pelo corpo que ela anima. (Cf. GILSON, 2006, p. 123).
} 
Agostinho, ao formular a distinção entre a sensação e os sensíveis, por sua vez, procura dissociar estritamente a realidade percebida e a sensação que temos dela, de modo que não considera a sensação propriamente uma forma de conhecimento, mas como elemento importante nos movimentos do espírito, enquanto os sensíveis, ao contrário, encontram-se inteiramente relacionados ao corpo. Igualmente dizemos que a paixão deverá existir na relação corpo/alma, isto é, na sua correlação mútua, pois a carne não imprime qualquer movimento sem a união com a alma. Agostinho, apesar de afirmar que a sensação é própria da alma, insiste que esta necessita dos estímulos corpóreos para se manifestar.

Em colóquio sobre a experiência do sentir diante da beleza da música, Agostinho deduz que se a beleza é fresta que liga o mundo sensível ao mundo inteligível, aproximando o humano ao divino, por sua vez, a música pode ser a mediação privilegiada pela qual acessamos essa fresta. Com efeito, a beleza da música tocou a alma de Agostinho ao entrar na Catedral de Milão, que chorou ao ouvir o canto dos hinos sacros compostos por Ambrósio. Sua breve impressão, naquele momento, é que o canto sacro nos conduz ao êxtase, na verdade, quando amamos a beleza e a harmonia do canto, amamos a luz (Epístola 101,3). Agostinho relata em suas Epístolas que ao decidir sobre o projeto da escrita do De musica, movido por um imenso desejo de contemplar a beleza, quis também compor uma introdução ao estudo da verdade, porque beleza, verdade e bondade são indissociáveis (ibidem, 101.3). Em matéria de harmonia, logo vemos o universo, o homem e a história, mas, no universo o lugar privilegiado da beleza é o homem, com a perfeição de seu corpo, as maravilhas de sua memória, com a capacidade de sua arte, com o amor a sabedoria. Na harmonia há toda potência do Cosmos (TRAPÈ, 2017, p. 384).

No Livro X de Confissões, Agostinho, em depuração dos sentidos da alma, evoca o imenso poder da memória para encontrar a direção e ascender até àquele que nos criou. Ao prescrutar o poder da memória, dirige seu pensamento aos "vastos palácios da memória, onde estão tesouros de inumeráveis imagens veiculadas por toda a espécie de coisas que se sentiram" (Confissões, X.8.12). Para o hiponense, a memória humana é infinita, nela se encontra o mistério insondável da marca distintiva do homem em relação aos outros seres vivos. Esta parte distinta da memória que o transcende é considerada a parte superior da mens, onde habitam as noções de ordem e verdade.

Como é grande esta potência da memória; tão grande, meu Deus, esse amplo e infinito santuário. [...] De fato, quando admiramos a grandeza das criaturas, a imensidão dos oceanos, as órbitas dos astros, o curso dos rios, o verde das montanhas, não conseguimos dizer apenas com os olhos que veem se não interiormente visse na minha memória, em espaços tão vastos como se os visse fora de mim, imagens impressas na memória" (Confissões X,8.15).

A memória é a retenção e conservação dos objetos sensíveis por parte da alma e das imagens que os sentidos percebe e são percebidos" (Cf. De trin., XI, 3, 6). Isto significa dizer que a alma tem a capacidade de guardar no seu interior as impressões que foram captadas no tempo, ela guarda em si mesma, a historicidade 
de sua relação com o mundo. Mas, além do poder de retenção e conservação, a memória é a condição de possibilidade de todo o conhecimento, portanto, a mais elementar das sensações, uma vez que pressupõe, antes a abertura de um horizonte de duração, portanto, depende do papel unificador da memória.

No Livro VI do De musica, Agostinho escreve que uma teoria da percepção sensível não poderia está dissociada da ação silenciosa da memória, pois se ouvir significa sempre ouvir um som com uma determinada duração, e se ver significa sempre ver um objeto com uma determinada extensão, visão e audição implicam, sempre já, a memória de uma duração ou de uma extensão. Quando se ouve uma frase, ou uma palavra, ou uma sílaba apenas, a memória conserva no fim da audição a lembrança do seu início e de todos os seus instantes intermédios, de tal modo que lhe é possível adicioná-los uns aos outros, compreendendo cada sílaba como parte de um todo articulado. Além disso, se as audições passadas não tivessem sido conservadas pela memória, seria impossível compreender as audições futuras como captações de novos sons. Enquanto que para um homem normal a recordação de sons passados converte os sons a vir em sons desconhecidos e, por isso, dotados de uma estrutura prévia de sentido, o homem sem memória é incapaz de reconhecer ou ouvir o que quer que seja (Cf. mus., VI, 8,21). A memória representa o ato criador, através do qual se atribui uma forma e um sentido a algo que, antes, carecia de ambos. Dito de outro modo, a memória converte o presente em possibilidade, revelando o próprio tempo como um horizonte permanente de possibilidade.

Na memória estão conservadas as imagens do belo? Com efeito, na evocação da memória e por meio da razão, a alma pode vislumbrar os vestígios da beleza inteligível, lá onde se encontram, também, as verdades eternas, a justa proporção das partes acompanhada por certo encanto de ordem e cores (Epístola 3, 4). Na harmonia da arte musical está o simulacro da harmonia divina que permitiu ao hiponense escalar a alma, degrau em degrau até os divinos segredos da memória. "Acima daqueles degraus, a sabedoria mostra seu aspecto mais alegre e agradável e, com toda a sabedoria, ajuda seus amantes" (Epístola 101,3). Os ritmos da razão, que para Agostinho são os mais belos, nos possibilita suscitar na alma a recordação dos números supremos e reaproximar a alma de Deus (mus., VI 11, 31; 12, 36), ou seja, por meio da beleza sensível, a alma no seu esforço primordial de ascese pode contemplar a beleza da verdade suprema.

O ápice da noção de ascese agostiniana se encontra escrito nos capítulos nove e o dezessete do livro sexto (Cf. mus., VI, 9, 23; VI, 17, 57), momento em que Agostinho faz a exegese do majestoso hino ambrosiano ${ }^{6}$. Conforme a sua descrição, ao ouvir o hino de Ambrósio na Catedral de Milão não era apenas a

\footnotetext{
${ }^{6}$ Santo Ambrósio, bispo de Milão no final do sécúlo IV, parece ter introduzido no Ocidente latino uma prática litúrgica do canto dos Salmos por meio de coral antifónica, bem como o hinário para todos os fiéis, costumes que rapidamente se expandiram pelas igrejas de Itália, Gália e Espanha, constituindo o chamado canto ambrosiano. Ambrósio muito oportunamente, aliás, soube até utilizar o canto para congregar os fiéis à sua volta, aquando das investidas da imperatriz Justina que queria ocupar uma igreja cristã de Milão com as celebrações dos heréticos arianos. Agostinho narra precisamente o seu convívio com Ambrósio em algumas passagens de Confissões, IX, 7, 15; IX, 12, 32; XI, 23, 35.
} 
beleza e harmonia dos sons que vibravam aos seus ouvidos, mas o vigor das palavras citadas no verso, Deus creator omnium, que ecoavam na alma em gozo e transcendência. Quando a sensação dos sons produzida pelos acordes que chegam aos ouvidos, naquele instante a alma não cessava de experimentar o gozo, porque a harmonia eterna que regula as leis dos números tem sua consistência em Deus e não no som que atinge o ouvido, ou no sentido da audição, ou no ato de quem decide. Deve-se, portanto, admitir que esses ritmos também estão em nossa memória, lá onde também se encontra o espírito e os vestígios da Beleza (mus., VI, 2, 2).

Os vestígios da beleza em que se refere Agostinho é o conteúdo que a alma pode alcançar com os seus sentidos, isto é, os vestígios da beleza inteligível que encontramos na própria alma, portanto, transcende a beleza sensível, presente nos seres e agradável pelo esplendor da luz e das cores, das melodias, sabores e odores. Toda a criação divina manifesta esta beleza divina em medida, número, ritmo e harmonia. Na hierarquia ontológica das criaturas, "o ser humano ocupa uma posição privilegiada, portanto, mais alta porque mais perfeita, tal como o canto humano e mais perfeito que o canto do rouxinol, justamente por ser composto de palavras e conteúdo espiritual" (mus., 1, 4, 6).

Para Agostinho, Deus é o verdadeiro músico, pois Nele dizer é criar, e criar é musicar, modular, por que Ele é o summus modus. "Tudo criastes com numerus, pondus, mensura, esse é o acorde fundamental da criação, o compasso ternário que estruturam a criação ab origine" (ROSA, 2004, p. 21). A música sensível produzida pela ciência nos auxilia na ascese, por meio da beleza sensível que se faz presente, tanto na visão, como na escuta, na combinação das palavras e na harmonia dos ritmos. Para tanto, deveríamos usar a música para nos salvar do vácuo e atingir o repouso da alma. Mas, para tal é preciso afinar o nosso próprio instrumento interior, na dispersão não há como nos transpor para a fonte da unidade.

Como vimos, o ritmo da razão é capaz de ver nas coisas sensíveis, a causa invisível que constitui os entes cósmicos na sua beleza. Além da beleza sensível, a razão dá-se conta da beleza presente na alma. Indo mais além, a alma descobre na unidade divina o máximo grau de beleza, a Beleza em toda sua plenitude (mus.,VI, 10, 25). Como escreve o Apóstolo Paulo aos Romanos, "o visível nos conduz ao invisível" (Romanos, 1, 20), assim também o audível nos conduz ao inaudível da essência musical, ao verbum interius que canta em silêncio com a língua em repouso e a garganta em silêncio, canto quanto quiser.

A razão vê beleza lá onde existe proporção e ritmo ou unidade. Quase sempre afirmamos que a beleza visível é fruto da mútua simetria das partes entre si em relação ao todo. De fato, encontramos simetria nos belos corpos, nas esculturas, nos seres criados, tal como descobrimos beleza e harmonia nos ritmos e melodias. A alma se comove e goza diante de uma bela paisagem natural, de uma escultura, do inigualável brilho dos astros, de uma bem composta melodia. Contudo, será a simetria causa da beleza sensível? Na verdade, a alma, progressivamente, dirige seu olhar amante ao Uno, fonte de todas as gradações e manifestações do belo, que pode ser dito como primeira beleza. 
A alma colhe acima de si mesma, nos números eternos, nas regras da verdade, os critérios pelos quais avalia as harmonias causadoras de deleite estético, encontrando na unidade, o paradigma principal do ser, do conhecimento e da estimação estética. No exercício da visão e da audição, em conclusão, o ser humano entra em contato com os números corporais, decifrando-os através dos números eternos. O homem, dotado de visão e audição, sendo capaz de perceber a beleza, encontra sua especificidade na aptidão racional de interpretar $\mathrm{o}$ significado da beleza intencionada. Todas as coisas, de fato, existem, podem ser conhecidas, amadas e estimadas em sua beleza, porque são unas. A unidade é a marca que possibilita a existência de todos os seres, racionais e irracionais, em sua singularidade.

\section{CONSIDERAÇÕES FINAIS}

Levando-se em consideração que a alma produz a sensação e necessita do dado sensível captado pelo corpo, no entanto, como explicar que a alma permanece intocável pelo corpo, mesmo recebendo dele as impressões do mundo sensível? Agostinho apesar das inúmeras aporia enfrentadas no De musica, pretende responder algumas questões em torno desta problemática, sempre ancorando na dimensão espiritual da alma. Na medida em que considera a alma como realidade espiritual que anima a vida, e que está presente em todos os órgãos do corpo ao mesmo tempo, quando o corpo é afetado pelas realidades externas, essa afetação só se torna sensação quando a alma dirige a sua atenção para aquela parte do corpo afetada. Assim sendo, não é o corpo que, ao ser afetado, age sobre a alma, mas a alma que dirige sua atenção para a parte do corpo afetada, utilizando-se disso para gerar a sensação sem sofrer nenhuma ação do corpo (mus., VI, 5, 10).

Sendo assim, o corpo foi entendido por Agostinho, como instrumento a serviço da espiritualização da alma, isto é, quando o corpo faz uso de seus sentidos exerce sua função de existir sendo instrumento da alma. De fato, o corpo sofre as paixões da alma, a tristeza, a raiva, o desejo desenfreado, mas não é o corpo quem peca, quem peca é a vontade, ou seja, os pecados são da alma, pois não é o corpo que deseja, quem deseja é a alma, ou seja, o corpo não produz as dores do mundo. Entretanto, para reconhecer as afecções corporais, a sensação utiliza a memória, onde se encontram ocultadas as imagens que fazemos das coisas que não vemos, segundo Agostinho até mesmo os afetos estão memória. De sorte que, os ritmos da sensação são realizados pela memória (mus., VI, 6, 16), contudo mesmo no silêncio e, sobretudo no sono, recordo as paixões da alma no corpo como se a alma estivesse em plena atividade resistindo ou consentindo as paixões do corpo.

O percurso que se faz no itinerário da alma racional ao conhecimento de Deus no livro sexto do De musica, estimula Agostinho a buscar na tradição pitagórica a noção de número como princípio imaterial e ordenador das coisas. Na tradição pitagórica, o número é o fundamento do movimento e da harmonia, portanto, gerador da ordem. Através da ordem percebida por meio dos números, pode-se obter um conhecimento racional de ritmos e movimentos no qual nossos 
sentidos são capazes de perceber e experimentar. Os sentidos percebem os movimentos dos ritmos quando necessitam ativar os vestígios da harmonia superior que estão expressos no espírito (ORTEGA, 1988, p. 54). Todavia, os números 7 presentes na alma não podem ser produzidos apenas pelo corpo, mas sim devem estar em sintonia com o sentido interior.

De igual modo, a memória contém as noções e as regras inumeráveis dos números e das dimensões. Não foram os sentidos quem nos gravou estas ideias, porque estas não têm cor, nem som, nem cheiro, nem gosto, nem são táteis. Quando delas se fala, ouço os sons das palavras que as significam. Mas os números são uma coisa e as ideias que exprimem, outra; os primeiros soam diferentemente em grego e em latim. Porém as ideias nem são gregas nem latinas, nem de nenhuma outra língua. "[...] Mas esses números com que contamos são bem diferentes: não são as imagens dos números sensíveis. Por conseguinte, são mais reais" (Cf. Confissões X 12, 19, p.463).

\section{REFERÊNCIAS}

AUGUSTIN. Dialogues Philosophiques - IV La Musique - De Musica Libri Sex. Texte de L'edition Bénédictine, introduction, traduction et notes de Guy Finaert, A.A. París: Desclêe, de Brouwer et Cie, 1947.

La Genèse au sens littéral en douze livres. I-VII; VIII-XII. Traduction, introduction et notes par p. Agaësse et A. Solignac. Paris: Études Augustiniennes, 2001.

Diálogo sobre a Música. Tradução, introdução e notas por Claudiberto Fagundes. Porto Alegre, RS: Universidade Federal do Rio Grande do Sul, 2014

Diálogo Sobre a ordem. Tradução, introdução e notas de Paula Oliveira e Silva. Lisboa: Imprensa Nacional-Casa da Moeda, 2000.

Confissões. Tradução de Arnaldo do Espírito Santo, João Beato e Maria Cristina de Castro-Maia de Sousa Pimentel. Introdução de Manuel Barbosa da Costa Freitas. $2^{a}$ ed. Edição bilingue português/latim. Lisboa: Nacional-Casa da Moeda, 2004.

BRACHTENDORF, Johannes. Confissões de Santo Agostinho. Tradução de Milton Camargo Mota. São Paulo: Edições Loyola, 2008.

BREHIER, Emile. La Filosofía de Plotino. Traducción de Lucía Piossek Prebisch. Buenos Aires: Editorial Sudamericana, 1953.

\footnotetext{
${ }^{7}$ A noção de número retrata basicamente a antiguidade pitagórica e permanece na filosofia até a idade média. No aspecto ontológico, os números são as leis das coisas: todo movimento sensível está sujeito ao número e ao ritmo. Diz Agostinho, quando se investiga a grandeza da alma, sua imortalidade e outras altíssimas verdades, recorre-se a ajuda da matemática. O número se relaciona com a beleza e com a harmonia e, portanto, com o aspecto racional do cosmos. Para Agostinho, o número é a ponte entre o mundo sensível e o mundo inteligível. E por isso, os seres formam como um magnífico poema. Cf. CAPANAGA, Victorino. Obras de San Agustin, Introducción general y primeiros escritos. Ed. bilingue. Vol I. Trad. y org. Victorino Capanaga. Madrid, BAC, 1994. p. 5253.
} 
CAPANAGA, Victorino. Obras de San Agustin. Introducción general y primeiros escritos. Ed. bilingue. Vol I. Trad. y org. Victorino Capanaga. Madrid: BAC, 1994

FAGUNDES, Claudiberto. Notas introdutórias do De musica, diálogos filosóficos de Agostinho de Hipona. Tese doutoral. Universidade Federal do Rio Grande do Sul - UFRS, Porto Alegre, 2014

GILSON, Étienne. Introdução ao estudo de Santo Agostinho. Tradução Cristiane Negreiros Abbud Ayoub. São Paulo: Paulus, 2010

GILSON, Étienne e BOEHNER, Philotheus. Filosofia Cristã. Tradução e nota introdutória de Raimundo Vier. 12 ed. Petrópolis, RJ: Vozes, 2009

MAMMİ, Lorenzo. Deus cantor. In: Artepensamento. São Paulo: Companhia das Letras, 1994.

MAMMİ, Lorenzo. Santo Agostinho, o Tempo e a Música. 1998. 432 fs. Tese (Doutorado em Filosofia). Universidade de São Paulo, 1998.

ORTEGA, Alfonso. Notas introdutórias de La Musica. Obras completas de San Agustín. Ed. bilíngue latim/espanhol, Vol 34. Madrid, 1988.

PLOTINO, Enéada V, 8 [31]. Acerca da beleza inteligível. Tradução, introdução e notas de Luciana Gabriela E. C. Soares. Kriterion, n. 107, Junho/2003.

ROSA, José M. Silva. Da Ambiguidade da Música na Antiguidade tardia e no pensamento de Sto. Agostinho. Lisboa: LusoSofia, 2004.

TRAPÉ, Agostino. Agostinho, o homem, o pastor e o místico. Tradução de Francisco Evaristo Marcos e Marcos Roberto Nunes Costa. São Paulo: Scripta Publicações, 2017.

Recebido em: 07-01-2019

Aceito para publicação em: 14-12-19 